\title{
Dual-tasking over an extended walking distance is associated with falls among community-dwelling older adults
}

\author{
Kenichi Hirashima ${ }^{1,2}$ \\ Yumi Higuchi' \\ Masakazu Imaoka' \\ Emiko Todo' \\ Tomomi Kitagawa' \\ Tetsuya Ueda' \\ 'Graduate School of Comprehensive \\ Rehabilitation, Osaka Prefecture \\ University, Habikino Campus, \\ Habikino City, Osaka, Japan; ${ }^{2}$ Faculty \\ of Health and Welfare, Department \\ of Physical Therapy, Tokushima \\ Bunri University, Nishihamaboji, \\ Yamashiro Town, Tokushima City, \\ Tokushima, Japan
}

This article was published in the following Dove Press journal:

Clinical Interventions in Aging

I April 2015

Number of times this article has been viewed
Aim: Dual-task methods, in which walking is the primary task, are not sufficient for accurately screening for the risk of falls among healthy older adults. Therefore, the goal of this research was to investigate whether using a dual-task method over an extended walking distance can predict falls among community-dwelling older adults.

Methods: We enrolled independent community-dwelling adults aged $\geq 65$ years. Physical performance, cognitive function, psychological function, and a dual-task test were assessed at baseline. Our dual-task test required the subjects to walk $60 \mathrm{~m}$ while stepping over lines. The intervals between the lines ranged from $50-100 \mathrm{~cm}$ and were unequal. Falls and fall-related injuries were measured over a 12-month follow-up period using monthly postal surveys.

Results: Ninety-two of 118 subjects (mean age, $75.4 \pm 5.5$ years) completed the 12-month follow-up. Sixteen (17.4\%) of fallers had injurious falls or fell more than or equal to two times. There were no significant differences between the fallers and non-fallers, except in age and in the number of missteps during the dual-task test when walking $\geq 40 \mathrm{~m}$. The Kaplan-Meier analysis revealed that those who had more than one misstep while walking $\geq 40 \mathrm{~m}$ had a significantly higher incidence of injurious or multiple falls than those who had no missteps.

Conclusion: Our findings suggest that the dual-task method with an extended walking distance may be able to predict falls among community-dwelling older adults.

Keywords: cohort study, community-dwelling older adults, dual-task, falls

\section{Introduction}

Falls are a major health problem for older adults and society. Approximately $10 \%-30 \%$ of community-dwelling older adults fall at least once a year. ${ }^{1,2}$ Falls among older adults are caused by multiple factors that are intricately related. ${ }^{3,4}$ According to the American Geriatrics Society and British Geriatrics Society guidelines from 2011 for predicting falls among older adults, the major risk factors for falls are as follows: a history of greater than or equal to two falls per year, injurious falls, gait and balance problems, medications, impaired visual acuity, muscle weakness, and cardiac hypofunction. ${ }^{5}$

Dual-task methods have been reported to be useful for predicting falls among older adults. Lundin-Olsson et $\mathrm{al}^{6}$ conducted a study among care facility residents who were able to walk independently alone and found that stopping gait when talking can be a predictor of falls. They first reported that these results as measured by dual-task methods were related to falls among older adults. Subsequently, dual-task methods have been discussed as a screening tool for assessing the risk of falls. ${ }^{7-9}$ The dual-task method was composed of two tasks: a gait or postural task as the primary task and a cognitive or manual task as the secondary task. ${ }^{10-12}$ Over a period of 1 year, the time taken to complete the primary task was compared under the dual-task conditions. ${ }^{13,14}$
Correspondence: Kenichi Hirashima Graduate School of Comprehensive Rehabilitation, Osaka Prefecture University, 3-7-30 Habikino Campus, Habikino City, Osaka 583-8555, Japan $\mathrm{Tel}+8172950211$ I

Email hirashima@tks.bunri-u.ac.jp 
Beauchet et $\mathrm{al}^{10}$ conducted a systematic review of previous studies on dual-task methods. They suggested that screening for the risk of falls by using a dual-task method detected those who were likely to fall among individuals with any disorder or who were institutionalized. ${ }^{10}$ In contrast, a more difficult second task was related to the prediction of falls among community-dwelling older adults. ${ }^{10}$ Thus, existing dual-task methods are not sufficient for accurately screening for the risk of falls among community-dwelling older adults.

Falls among community-dwelling older adults are caused frequently by tripping while walking. Previous studies have shown that stepping performance while walking was associated with tripping. ${ }^{15-19}$ Stepping performance was measured by setting obstacles or targets on the walkway. The methods for conducting the measurement included numerous trials for observation of an accidental event (ie, tripping). Therefore, walking an extended distance, which was the primary task in dual-tasking, may be useful for assessing the risk of falls among community-dwelling older adults. Thus, the purpose of this study was to investigate whether a dualtask method over an extended walking distance can predict falls among community-dwelling older adults.

\section{Methods}

\section{Subjects}

The study subjects were volunteers from a community senior club who were aged $\geq 65$ years, lived independently, and were able to walk approximately $500 \mathrm{~m}$ without a cane. The exclusion criteria were the following: 1) a score of $<25$ on the Mini-Mental State Examination (MMSE);20 2) neurological and/or orthopedic disorders; and 3) previous operations on the spine and/or lower extremities. This study was conducted with the approval of the Research Ethics Committee of Osaka Prefecture University (2012PT10), and all subjects provided written informed consented to participate.

\section{Baseline assessment}

We conducted a 12-month prospective cohort study to examine the occurrence of falls after a baseline assessment.
Physical performance was assessed using the Timed Up and Go (TUG) test ${ }^{21}$ as a measure of dynamic balance. Maximum knee extension strength was assessed using a hand-held dynamometer ( $\mu$ Tas F-1; ANIMA, Tokyo, Japan). The extension strength was measured using the subjects' dominant leg and was calculated by dividing the measured value by the body weight (N/kg). ${ }^{22}$ The TUG and knee extension strength were each measured twice, with the higher value included in the analysis. Cognitive function was examined using the MMSE, and executive function was assessed using the Trail Making Test, Part A. ${ }^{23}$ The Geriatric Depression Scale ${ }^{24}$ and the Philadelphia Geriatric Center Morale Scale ${ }^{25}$ were used as indices on the presence, not state, of depressive symptoms, and subjective well-being. Fall-related self-efficacy was assessed by using the Falls Efficacy Scale. ${ }^{26}$

\section{Extended walking distance dual-task assessment}

During the dual-task test, the subjects were required to walk down a $10 \mathrm{~m}$ walkway and to return three times $(60 \mathrm{~m}$ in total) at their usual speed without stepping on the unequal lines. ${ }^{27}$ The unequal lines were employed to consider variety of the step length of the subjects. Figure 1 shows the walkway used in this study, which was gray and measured $10 \mathrm{~m} \times 90 \mathrm{~cm}$. Twelve yellow lines (10 cm wide) were drawn on the walkway. The intervals between the lines ranged from $50-100 \mathrm{~cm}$ and were unequal. The subjects had several practice trials in order to completely understand the dualtask test. Missteps were defined as stepping on the line and were identified by an examiner who walked alongside the subjects. No feedback on the missteps was provided to the subjects. The time and the number of missteps were recorded every 20,40 , and $60 \mathrm{~m}$.

\section{Follow-up}

After the baseline assessment, the subjects were followed for 12 months for falls and fall-associated injuries. A fall was defined as the accidental contact of any body part, except for the plantar, with a low area such as the floor or
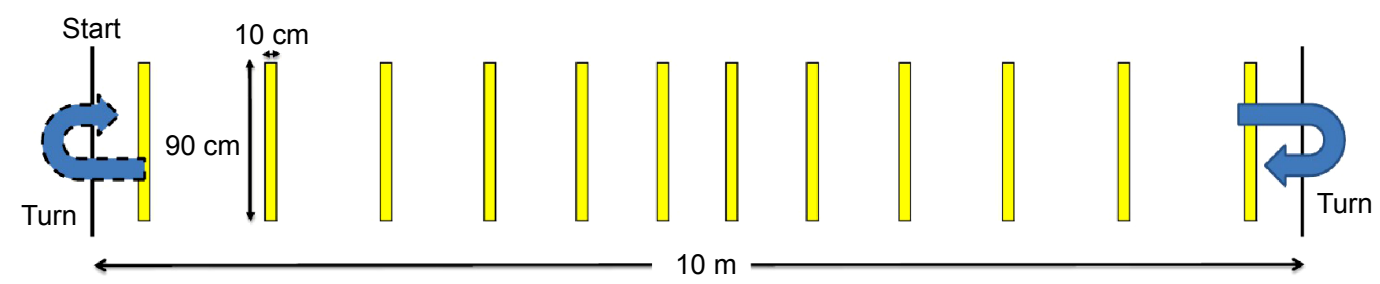

Figure I The $10 \mathrm{~m}$ walkway used in the extended walking distance dual-task assessment. 
the ground. ${ }^{28}$ Subjects who were injured because of falls or those who fell more than or equal to two times were defined as fallers. According to the guidelines for predicting falls, ${ }^{5}$ older community-dwelling persons reporting only a single fall were considered to be at low risk for falls. Information on falls during the follow-up period was collected by monthly postal surveys and telephone calls.

\section{Statistical analysis}

To compare the baseline characteristics of fallers with the nonfallers, an unpaired $t$-test was used for continuous variables, the Mann-Whitney $U$ statistic was used for non-normally distributed variables, and the chi-square test was used for categorical variables. The subjects were divided into two groups according to the presence of missteps during the dual-task test - the non-misstep group and the misstep group, the group in which subjects made at least one misstep. The elapsed time to the first injurious fall or the second fall event was analyzed using the Kaplan-Meier curves, and comparisons were made using the log-rank test. In addition, to examine the influence of age on falls, the subjects were divided into two groups according to the median age of all subjects, and they were compared using the Kaplan-Meier method and the log-rank test. All the statistical analyses were performed using
SPSS Statistics 21 (IBM Corporation, Armonk, NY, USA). $P$-values $<0.05$ were considered statistically significant.

\section{Results}

During the 12-month follow-up, 16 subjects withdrew, resulting in $92(85.2 \%)$ remaining in the final analyses. The reasons for withdrawal were hospitalization due to factors other than falls $(n=4)$ and loss to follow-up or refusal to be followed $(n=12)$. Of the 92 subjects, $16(17.4 \%)$ were injured because of falls, or they fell more than one time during the 12-month follow-up. These individuals were classified as fallers.

Table 1 shows a comparison of the baseline characteristics. There were no significant differences between the fallers and non-fallers, except in age. Figure 2 shows the fallers and non-fallers (\%) who misstepped during the dual-task test at baseline. There was no significant difference between the groups in the $20 \mathrm{~m}$ observation. However, in the $40 \mathrm{~m}$ and $60 \mathrm{~m}$ observations, the percentage of those who made missteps was significantly higher in the fallers than in the non-fallers. In the $40 \mathrm{~m}$ observation, eleven of 16 fallers and 31 of 76 non-fallers were observed making missteps ( $40 \mathrm{~m}$; $P=0.041$ ). In the $60 \mathrm{~m}$ observation, 13 of 16 fallers and 40 of 76 non-fallers were observed making missteps $(60 \mathrm{~m}$; $P=0.035)$.

Table I Baseline characteristics of subjects classified by falls during the follow-up period

\begin{tabular}{|c|c|c|c|}
\hline Characteristics & Faller $(n=16)$ mean $\pm S D$ & Non-faller $(n=76)$ mean \pm SD & $P$-value \\
\hline Age (years) & $78.1 \pm 5.6$ & $74.9 \pm 5.3$ & 0.034 \\
\hline Male, n (\%) & $3(18.8 \%)$ & II (I4.3\%) & 0.704 \\
\hline Body mass index $\left(\mathrm{kg} / \mathrm{m}^{2}\right)$ & $23.5 \pm 2.4$ & $23.2 \pm 2.6$ & 0.637 \\
\hline Height (cm) & $154.2 \pm 9.3$ & $153.6 \pm 5.7$ & 0.817 \\
\hline Weight (kg) & $56.4 \pm 10.9$ & $54.8 \pm 7.4$ & 0.578 \\
\hline Quadriceps strength/wt (N/kg) & $4.9 \pm 1.2$ & $4.4 \pm 1.4$ & 0.183 \\
\hline MMSE (0-30) & $28.1 \pm 1.6$ & $28.1 \pm 1.7$ & 0.861 \\
\hline TMT-A (s) & $130.9 \pm 40.7$ & $131.2 \pm 47.9$ & 0.986 \\
\hline GDS (0-15) & $2.2 \pm 2.2$ & $2.8 \pm 1.7$ & 0.333 \\
\hline PGC $(0-17)$ & $11.9 \pm 3.5$ & $12.2 \pm 3.4$ & 0.720 \\
\hline FES $(10-100)$ & $18.4 \pm 12.1$ & $|5.2 \pm 1| .2$ & 0.192 \\
\hline TUG (s) & $8.3 \pm 1.1$ & $8.4 \pm 1.5$ & 0.792 \\
\hline \multicolumn{4}{|l|}{ Usual gait time (s) } \\
\hline $20 \mathrm{~m}$ & $18.7 \pm 3.1$ & $18.4 \pm 2.6$ & 0.744 \\
\hline $40 \mathrm{~m}$ & $37.1 \pm 5.6$ & $37.3 \pm 5.2$ & 0.909 \\
\hline $60 \mathrm{~m}$ & $56.1 \pm 8.1$ & $56.4 \pm 8.2$ & 0.886 \\
\hline \multicolumn{4}{|l|}{ Dual-task test (s) } \\
\hline $20 \mathrm{~m}$ & $20.3 \pm 3.6$ & $20.4 \pm 4.3$ & 0.916 \\
\hline $40 \mathrm{~m}$ & $40.6 \pm 6.5$ & $4 I .1 \pm 8.3$ & 0.842 \\
\hline $60 \mathrm{~m}$ & $61.6 \pm 9.5$ & $61.8 \pm 12.5$ & 0.942 \\
\hline
\end{tabular}

Abbreviations: MMSE, Mini Mental State Examination (the score range is 0 to 30, with a higher score indicating better memory); TMT-A, Trail Making Test Part A (the time is a shorter time indicating better attention function); GDS, Geriatric Depression Scale (the score range is 0 to I5, with a higher score indicating worse depression); PGC, Philadelphia Geriatric Center Morale Scale (the score range is 0 to 17, with a higher score indicating better morale); FES, Falls Efficacy Scale (the score range is 10 to I00, with a higher score indicating better efficacy); TUG, Timed UP and Go-Test (the time is a shorter time indicating better motor function). 


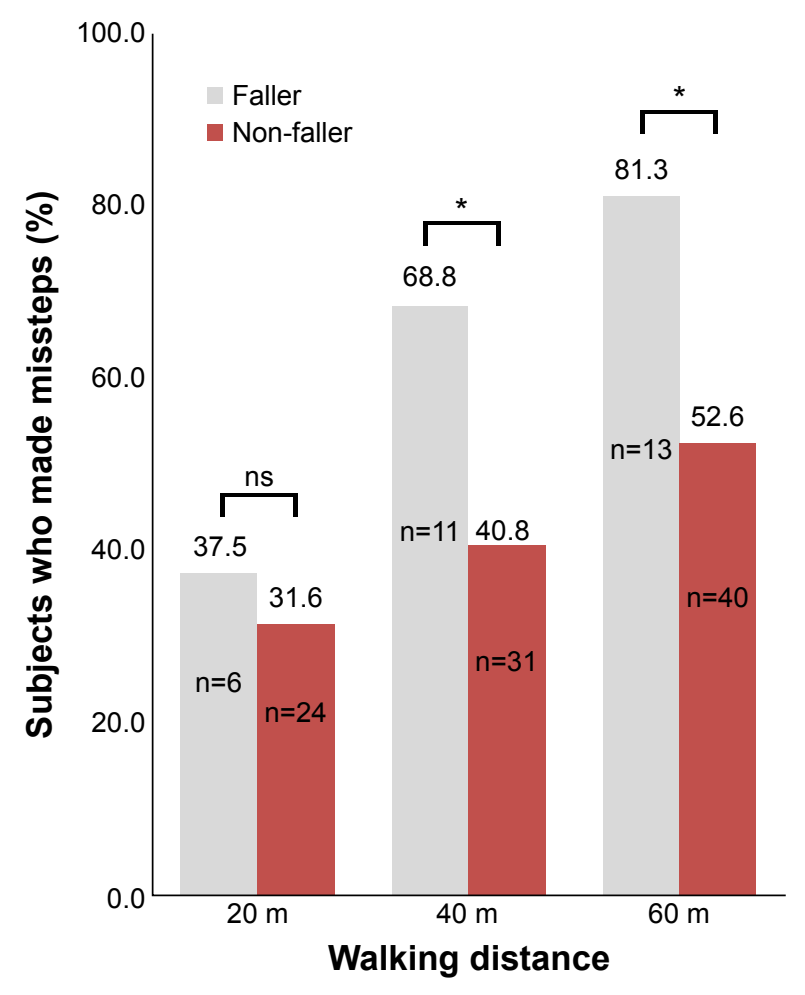

Figure 2 Subjects who made missteps during the dual-task test at baseline. Note: $* P<0.05$.

Abbreviation: ns, not significant.

Figure 3 shows the comparisons of the incidence of injurious falls or more than two falls within a 12-month period. Although there was no significant difference between the non-misstep group and the misstep group in the $20 \mathrm{~m}$ observation, the misstep group had a significantly higher incidence of injurious falls or multiple falls than the nonmisstep group during the $\geq 40 \mathrm{~m}$ walk ( $40 \mathrm{~m} ; P=0.042,60$ $\mathrm{m} ; P=0.038)$. To examine the influence of age, the subjects were divided into two groups according to the median age ( $\leq 75$ years old) of all subjects. We compared the incidences of injurious falls or more than or equal to two falls between the groups; however, no significant difference was observed $(P=0.366)$.

\section{Discussion}

The major finding of the present study was that the subjects who had made missteps during the dual-task test with an extended walking distance of $\geq 40 \mathrm{~m}$ were significantly more likely to be fallers. There was no significant difference between the groups in the $20 \mathrm{~m}$ observation.

Individuals with a TUG time of $\geq 13.5$ seconds are considered to be frail older adults. ${ }^{11}$ All the subjects in the present study took $<13.5$ seconds to complete the TUG test, and the mean of TUG tests for fallers and non-fallers was 8.3 seconds and 8.4 seconds, respectively. Furthermore, both groups had high cognitive function with a mean score on the MMSE of 28.1. These findings indicate that the subjects in this study were older adults with good physical and cognitive function.

Our extended walking distance dual-task test was composed of two tasks, walking $60 \mathrm{~m}$ as the primary task, and avoiding stepping on the unequal $10 \mathrm{~cm}$-wide lines as the secondary task. In previous cohort studies with a focus on community-dwelling older adults, which used the TUG and a $3 \mathrm{~m}$ walk as primary tasks, a cognitive task (eg, an arithmetic task or solving two simple calculations) was utilized as the secondary task..$^{13,29}$ The findings of these studies have not revealed any correlations between the tasks and the occurrence of falls. In addition, in previous studies on healthy older adults, accidental tripping during walking was observed. There studies also combined the stepping over gait (eg, observations of targets in contact with three-dimensional or visual obstacles that can cause a fall) with a cognitive task (eg, the n-back test or reaction task). ${ }^{15,17}$ The subjects were required to step over obstacles on a straight walkway of approximately $10 \mathrm{~m}$, and they were observed in a remarkable number of trails. Indeed, these studies showed that many observations over a great distance were necessary to observe accidental tripping in older adults. Therefore, in the present study, we selected a $60 \mathrm{~m}$ walking distance for the dual-task test. The originality of our study was in the sequence of the lines older adults had to avoid stepping upon. The subjects were required to walk $60 \mathrm{~m}$ on the $10 \mathrm{~m}$ walkway on which 12 unequal lines were drawn. Thereby, the subject had the secondary task of avoiding stepping on a line 72 times (as the subject doubled-back three times). Compared to the previous studies, the secondary task of avoiding stepping on something was conducted more frequently in this study. Thus, the extended walking distance dual-task test may show the relation between the tasks and the occurrence of falls among community-dwelling older adults.

There were some limitations to this study. First, we did not directly compare the dual-task test with a single task assessment such as the TUG test to provide a comparison on the difference in sensitivity and specificity of predicting falls using the two assessment tools. Second, the inter-rater reliability of our dual-task test is unclear; therefore, we must clarify this in the future.

Our findings suggest that using the dual-task method over an extended walking distance may help to predict falls 
A

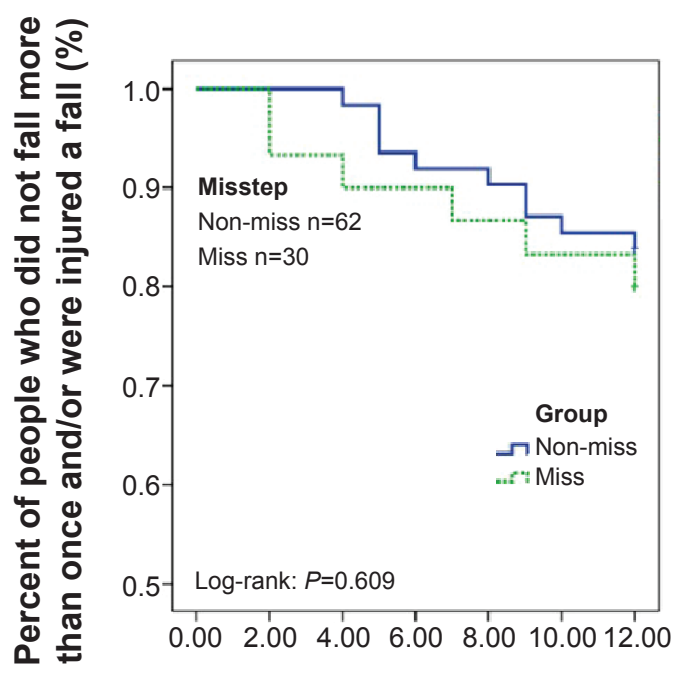

Months
B

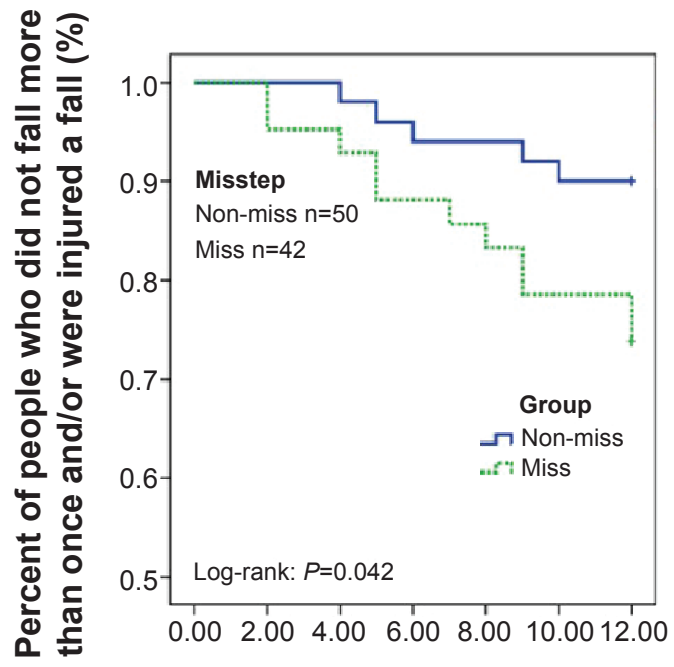

Months

C

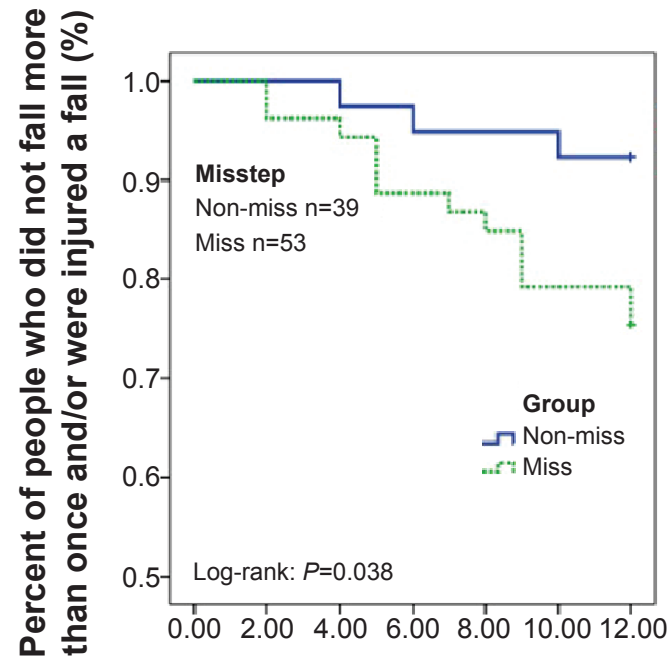

Months

Figure 3 Plot of Kaplan-Meier survival analysis for the number of missteps during the dual-task test.

Notes: (A) Survival curves at $20 \mathrm{~m}$ observation distance; (B) survival curves at $40 \mathrm{~m}$ observation distance; (C) survival curves at $60 \mathrm{~m}$ observation distance.

Abbreviations: Non-miss, the group of subjects who made no missteps; Miss, the group in which subjects made missteps at least once during the dual-task test at baseline.

among community-dwelling older adults. This dual-task method might be clinically useful to identify older adults who, in spite of good physical and cognitive function, have a high risk of falling.

\section{Acknowledgments}

We would like to extend our sincere appreciation to the subjects who participated. We also wish to thank Keizo Hosoi (community senior club member) for coordinating the research study.

\section{Disclosure}

The authors report no conflicts of interest in this work.

\section{References}

1. Tromp AM, Smit JH, Deeg DJ, Bouter LM, Lips P. Predictors for falls and fractures in the Longitudinal Aging Study Amsterdam.J Bone Miner Res. 1998;13(12):1932-1939.

2. Tinetti ME, Speechley M, Ginter SF. Risk factors for falls among elderly persons living in the community. N Engl J Med. 1988;319(26): 1701-1707.

3. Campbell AJ, Borrie MJ, Spears GF. Risk factors for falls in a community-based prospective study of people 70 years and older. J Gerontol. 1989;44(4):M112-M117. 
4. Lord SR, Clark RD, Webster IW. Visual acuity and contrast sensitivity in relation to falls in an elderly population. Age Ageing. 1991;20(3): 175-181.

5. Panel on Prevention of Falls in Older Persons, American Geriatrics Society and British Geriatrics Society. Summary of the Updated American Geriatrics Society/British Geriatrics Society clinical practice guideline for prevention of falls in older persons. J Am Geriatr Soc. 2011;59(1):148-157.

6. Lundin-Olsson L, Nyberg L, Gustafson Y. "Stops walking when talking" as a predictor of falls in elderly people. Lancet. 1997;349(9052):617.

7. Beauchet O, Dubost V, Gonthier R, Kressig RW. Dual-task-related gait changes in transitionally frail older adults: the type of the walkingassociated cognitive task matters. Gerontology. 2005;51(1):48-52.

8. Hollman JH, Kovash FM, Kubik JJ, Linbo RA. Age-related differences in spatiotemporal markers of gait stability during dual task walking. Gait Posture. 2007;26(1):113-119.

9. Woollacott M, Shumway-Cook A. Attention and the control of posture and gait: a review of an emerging area of research. Gait Posture. 2002;16(1):1-14.

10. Beauchet $\mathrm{O}$, Annweiler C, Dubost V, et al. Stops walking when talking: a predictor of falls in older adults? Eur J Neurol. 2009;16(7):786-795.

11. Shumway-Cook A, Brauer S, Woollacott M. Predicting the probability for falls in community-dwelling older adults using the Timed Up and Go Test. Phys Ther. 2000;80(9):896-903.

12. Bisson EJ, McEwen D, Lajoie Y, Bilodeau M. Effects of ankle and hip muscle fatigue on postural sway and attentional demands during unipedal stance. Gait Posture. 2011;33(1):83-87.

13. Vaillant J, Martigné P, Vuillerme N, et al. [Prediction of falls with performance on Timed "Up- and -Go" and one-leg-balance tests and additional cognitive tasks]. Ann Readapt Med Phys. 2006;49(1):1-7. French.

14. Beauchet O, Allali G, Annweiler C, et al. Does change in gait while counting backward predict the occurrence of a first fall in older adults? Gerontology. 2008;54(4):217-223.

15. Schrodt LA, Mercer VS, Giuliani CA, Hartman M. Characteristics of stepping over an obstacle in community dwelling older adults under dual-task conditions. Gait Posture. 2004;19(3):279-287.

16. Chapman GJ, Hollands MA. Evidence that older adult fallers prioritise the planning of future stepping actions over the accurate execution of ongoing steps during complex locomotor tasks. Gait Posture. 2007;26(1):59-67.
17. Chen HC, Schultz AB, Ashton-Miller JA, Giordani B, Alexander NB, Guire KE. Stepping over obstacles: dividing attention impairs performance of old more than young adults. J Gerontol A Biol Sci Med Sci. 1996;51(3):M116-M122.

18. Muir BC, Haddad JM, Heijnen MJ, Rietdyk S. Proactive gait strategies to mitigate risk of obstacle contact are more prevalent with advancing age. Gait Posture. 2015;41(1):233-239.

19. Shin S, Demura S, Watanabe T, Kawabata H, Sugiura H, Matsuoka T. Relationship between the obstacle height cognition and step movement in the elderly. J Physiol Anthropol. 2012;31:27.

20. Folstein MF, Folstein SE, McHugh PR. "Mini-mental state". A practical method for grading the cognitive state of patients for the clinician. J Psychiatr Res. 1975;12(3):189-198.

21. Podsiadlo D, Richardson S. The timed "Up and Go": a test of basic functional mobility for frail elderly persons. J Am Geriatr Soc. 1991; 39(2):142-148

22. Bohannon RW. Reference values for extremity muscle strength obtained by hand-held dynamometry from adults aged 20 to 79 years. Arch Phys Med Rehabil. 1997;78(1):26-32.

23. Reitan RM. Validity of the Trail Making test as an indicator of organic brain damage. Percept Mot Skills. 1958;8(3):271-276.

24. Sheikh JI, Yasavage JA. Geriatric Depression Scale (GDS). Recent evidence and development of a short version. Clin Gerontol. 1986;5(1-2): 165-173.

25. Lawton MP. The Philadelphia Geriatric Center Morale Scale: a revision. J Gerontol. 1975;30(1):85-89.

26. Tinetti M, Richman D, Powell L. Falls efficacy as a measure of fear of falling. J Gerontol. 1990;45(6):P239-P243.

27. Hirashima K, Higuchi Y, Ishihara M, Imaoka M, Toudou E, Kitagawa T. [The relationship between falls by community-dwelling elderly and missteps in the stepping over gait task]. Rigakuryoho Kagaku. 2014;29(1):19-24. Japanese.

28. Gibson MJ. Falls in Later Life. Improving the Health of Older People. In: A World View. Kane RL, et al. Oxford: Oxford University Press. 1990:296-315.

29. Stalenhoef PA, Diederiks JP, Knottnerus JA, Kester AD, Crebolder HF. A risk model for the prediction of recurrent falls in communitydwelling elderly: a prospective cohort study. J Clin Epidemiol. 2002;55(11):1088-1094.
Clinical Interventions in Aging

\section{Publish your work in this journal}

Clinical Interventions in Aging is an international, peer-reviewed journal focusing on evidence-based reports on the value or lack thereof of treatments intended to prevent or delay the onset of maladaptive correlates of aging in human beings. This journal is indexed on PubMed Central, MedLine,

\section{Dovepress}

CAS, Scopus and the Elsevier Bibliographic databases. The manuscript management system is completely online and includes a very quick and fair peer-review system, which is all easy to use. Visit http://www.dovepress. com/testimonials.php to read real quotes from published authors. 